\title{
El epitafio como modalidad epigramática en el Siglo de Oro (con ejemplos de Quevedo y Lope de Vega)'
}

\author{
SAGRARIO LÓPEZ POZA
}

Universidade da Coruña

\section{Resumem}

Entre las modalidades epigramáticas procedentes de la Antología Planudea que sirvieron de modelos de imitación a los poetas españoles de los siglos XVI y XVII, han de considerarse los epitafios. Los poetas aprendían a adaptar las marcas constantes del género clásico al español y su sistema poético durante su etapa de estudiantes, generalmente mediante la práctica de traducción e imitación de epigramas de las selecciones de la Antología Planudea realizadas por Soter, Cornarius o Henri Estienne II. Escribir epitafios se convirtió en un ejercicio literario con el que practicar el género epidíctico (eficaz para ostentar el ingenio personal) de capital importancia para el éxito de un hombre de letras en la corte. Pero el poeta que escribía epitafios debía mantener las marcas propias del género epigramático tanto en la estructura, la condición elocutiva, las voces del discurso, el estilo .... En este trabajo se realiza un análisis de esas peculiaridades de adaptación a través de ejemplos de epitafios de Lope de Vega y Quevedo.

\begin{abstract}
Epitaphs are amongst the epigrammatic types derived from the Planudean version of the Greek Anthology that served as models for 16th- and 17th-century Spanish poets, who learned to adapt the style of the classical genre to Spanish prosody in their student days. This they did generally by translating and imitating epigrams from selections taken from the Planudes edition by scholars such as Soter, Cornarius and Henri Estienne II. Writing epitaphs became a literary exercise in the epidictic genre with a view to showing off poetic ingenuity, a quality that could prove to be an asset for the man of letters at court. However, writing epitaphs meant maintaining
\end{abstract}

1 Este trabajo se inscribe en el proyecto de investigación y desarrollo tecnológico cofinanciado por el Plan Nacional de Investigación Científica, Desarrollo e Innovación Tecnológica (I + D), Ministerio de Educación y Ciencia de España y el Fondo Europeo de Desarrollo Regional (FEDER): 'Biblioteca Digital Siglo de Oro II: Relaciones de sucesos, Polianteas y fuentes de erudicion en la Edad Moderna (catalogacion, digitalizacion y difusion via Internet)', código: HUM2006-07410/FILO. 
the characteristics of the epigrammatic genre, not only in its structure, but also in terms of locution, discursive voice, style and so on. The peculiarities of adaptation are analysed in this article via epitaphs written by Lope de Vega and Quevedo.

Durante mucho tiempo, al hablar de epigrama en la literatura española, por lo general se evocaba el siglo XVIII, que si bien fue rico en la producción epigramática, la variedad practicada estaba restringida a la satírica y didáctica. Muy pocas veces los lectores actuales asocian ese género a la ingente producción de epigramas en el Siglo de Oro, y a la riquísima variedad en temas y formas que se practicó. Esto es debido, en parte, a que durante el siglo XX, el interés de la crítica se volcó más en el sistema petrarquista, mientras que las realizaciones neoclásicas que trataron de aprehender modelos genéricos de la antigüedad latina y dotarlos de una nueva 'forma' vernácula (como la Oda, Elegía, Égloga, Epístola), tuvieron que esperar largo tiempo a que los investigadores se ocuparan de ellas. ${ }^{2}$ Pero el Epigrama, aun formando parte también de esas adaptaciones de la poesía clásica, ha seguido siendo el patito feo de los estudios poéticos, y no ha llegado a dedicarse a él un estudio monográfico profundo.

Mi propósito es señalar que gran parte de los epitafios en español creados por nuestros poetas del Siglo de Oro llevan las marcas del género epigramático al que pertenecen, tanto en su estructura métrica como temática, en rasgos de estilo y fórmulas propias que fueron heredadas de la Antología Griega y sus imitadores renacentistas.

Como es sabido, el epitafio es uno de los géneros poéticos más practicados durante los siglos XVI y XVII, tanto en latín como en lenguas vulgares. Empleado desde la Antigüedad, el epitafio había adquirido en el mundo romano un notable desarrollo que había ido ampliando las escuetas menciones sobre el difunto que solían esculpirse en las lápidas mortuorias hasta llegar a convertirlo en un elogio fúnebre en verso, de cuidada factura literaria. Frente al epitafio clásico sepulcral en que priman los elementos puramente denotativos, por ejemplo comenzar con el nombre del difunto, seguido de su filiación, su patria, cargos, dignidades, el nombre de quienes colocaron la inscripción, la edad del finado y el día de su muerte... se fue desarrollando un gusto por el predominio de elementos connotativos procedentes en su mayor parte de la tradición clásica griega. Con el Renacimiento y el aprecio por la antigüedad clásica, se puso de moda la práctica del arte lapidaria y el gusto por coleccionar inscripciones reales o crearlas de forma ficticia, a imitación de las que aparecían en las ruinas veneradas de la civiliza-

2 Notable ha sido el esfuerzo del grupo PASO, dirigido por Begoña López Bueno, que impulsó el interés por esas formas y géneros en la década de los 90 y que ha producido volúmenes con estudios sobre La oda (1993), La Elegía (1996), La Epístola (2000), La Égloga (2002). También han tenido interés para lo que nos ocupa otros encuentros organizados por este grupo dedicados a La Silva (1990), a Las 'anotaciones' de Fernando de Herrera (1996) y a estudios sobre el Canon (2003), cuyos trabajos han sido ya publicados. 
ción romana. ${ }^{3}$ El epitafio literario fue ganando terrero a partir del siglo XV y frente a otros géneros heredados de la literatura clásica en progresivo desuso, su cultivo, tanto en latín como en español, perduró con mucha fuerza en la literatura barroca. Ello no es ajeno a un hecho de gran relevancia: la divulgación y recepción de la Antología Griega llevada a Italia por los sabios que huyeron de Constantinopla cuando fue tomada por los turcos en 1453 y sobrevino la caída del Imperio Romano de Oriente (conocido a partir del siglo XVII como Imperio Bizantino).

Como he señalado en otro lugar (López Poza 2005: 67), los españoles que estuvieron en contacto con Italia en el siglo XVI mostraron un interés y hasta pasión por los epigramas griegos; de ello nos han quedado testimonios manuscritos y colecciones de escolios valiosos y relevantes. El interés de humanistas españoles por la Antología Griega no pudo reflejarse en una producción impresa debido a las dificultades que sufría la imprenta en España, sobre todo a partir de la segunda mitad del siglo XVI, y a la falta de mecenas que impulsaran los estudios no estrictamente vinculados con la religión. Pero a pesar de la cerrazón contrarreformista que dificultó la difusión del trabajo de importantes profesores de las universidades de Alcalá de Henares y Salamanca, sus enseñanzas lograron crear patrones de influencia en la primera mitad del siglo XVI y los primeros años de la segunda mitad del siglo que luego se desarrollarían de manera más firme hasta finales del XVI. La utilidad de los epigramas para la enseñanza, la difusión a precios asequibles de selecciones impresas de la Antología Planudea con versiones en latín de los epigramas, el influjo de humanistas como Alciato, que se inspiraron para sus creaciones en la Antología, y sobre todo, la labor de los comentaristas de los emblemas de este italiano - los del Brocense, Mignault, Diego López -, que ponían a disposición de maestros y poetas un rico arsenal de fuentes que podían servir de modelos para la aemulatio, garantizaron una prolongada y fecunda influencia de la Antología Griega en España.

Los Epitafios y Encomia forman la sección más larga de la Antología Griega (ocupaban los libros III y parte del I de la versión Planudea - la única que conocieron los autores que nos interesan ${ }^{4}-$ y después, en la Palatina, ocuparon

3 El Humanista Benito Arias Montano poseía en su casa de Miraflores, en Sevilla, un museo de inscripciones antiguas que le pudieron servir de modelo para los epitafios que compuso. Otro de sus amigos, Francisco Pacheco, fue en el siglo XVI el principal autor de inscripciones para Sevilla en edificios monumentales y los de arquitectura efímera para las fiestas. Para detalles sobre el gusto por el arte lapidaria véase Tesauro 1741.

4 Conocemos como Antología Griega una recopilación de epigramas griegos, canciones, epitafios y ejercicios retóricos que reúne material de los siglos VII a.C. hasta el año 1000 de nuestra era y que ha llegado hasta nosotros a través de dos colecciones principales: la Antología Planudea, realizada por Máximo Planudes en 1301, y la Antología Palatina, que recibió su nombre del único manuscrito en que se conserva (Palatinus 23, en Heidelberg). Así como muchos estudiosos identifican Antología Griega con Antología Palatina, para quienes nos interesamos en el Siglo de Oro es muy importante precisar que los autores con los que trabajamos sólo pudieron conocer impresa la versión planudea, pues el manuscrito palatino fue hallado en 1607 por Salmasius, pero no llegó a ser impreso hasta finales del siglo XVIII. Es posible que algunos eruditos consiguieran manuscritos apógrafos del material 
el libro VII los epitafios y el IX los Epigramas epidícticos.

Los poetas de los siglos XVI y XVII aprendieron a componer epitafios en la escuela. Su práctica era casi cotidiana, tanto en las escuelas municipales como en las eclesiásticas y desde luego en los colegios de jesuitas. La Ratio Studiorum ${ }^{5}$ (norma que debían seguir todos los colegios jesuíticos en el mundo) da instrucciones al profesor de Retórica y al de Humanidades para llevar a cabo esas prácticas. ${ }^{6}$

Existían modelos accesibles en las varias selecciones de la Antología Planudea (véase bibliografía al final) editadas por Joannes Soter (Colonia, 1525, luego reeditada en 1528 y 1544), Janus Cornarius (Basilea, 1529) y sobre todo en la de Henri Estienne II, publicada en 1570 en Ginebra, que realizó una selección de la Antología Griega pensando en estudiantes jóvenes, y por lo tanto expurgada de todo lo que pudiera considerarse inconveniente o indecente para la moral, lo que poco después imitaron los jesuitas, que imprimían en sus propias prensas las selecciones de la Planudea para sus alumnos (López Poza 2005).

La selección de Estienne, en un asequible tamaño en octavo, incluye una traducción en prosa latina de cada epigrama, realizada por él mismo, luego una o dos versiones en verso (también suyas, y a veces otra de su amigo Melissus) y a continuación ofrece otras versiones en verso tomadas de ediciones anteriores. Su antología pretendía también motivar para la composición de versos en latín y, naturalmente, la imitación en español era ejercicio muy frecuente. ${ }^{7} \mathrm{Su}$ selección tiene una representación selectiva del contenido total de la Antología Planudea. De los casi 260 epigramas que selecciona, la distribución tipológica es bien elocuente. Destaca la presencia de los epigramas anecdóticos y morales $(37,7 \%)$. En casi la misma proporción (cerca del $20 \%$ ) están los epitafios y los que describen obras de arte. Los satíricos son un $12,7 \%$ y los dedicatorios y eróticos han de conformarse con un puesto humilde (entre el 4 y el 5\%). La selección de Estienne contribuyó de manera importante a inclinar el interés hacia cierto tipo de epigramas griegos en todas sus modalidades que los alumnos traducían, analizaban, parafraseaban y al fin imitaban en su propia lengua. El epitafio ocupaba un lugar bastante destacado, junto con otras modalidades vinculadas al género retórico epidíctico (genus demostrativum).

La característica principal del género epidíctico es su ausencia de utilidad práctica; es un estilo elaborado que permite dar fe de las facultades del orador,

nuevo que contenía la Palatina, pero la mayoría de quienes conocían la Antología griega, desde el siglo XV al final del XVIII lo hicieron a través de la colección planudea o a través de las muchas selecciones que se hicieron impresas de ella, y sobre todo aquellas que ofrecían la doble versión en griego y en latín. A partir de 1813-14, en la edición que hizo Friedrich Jacobs de la Palatina, la versión planudea cayó en desuso. Ver S. López Poza, 2005.

5 Ver Eusebio Gil, 1992.

6 Ibid., epígrafes: Reglas del profesor de Retórica y Reglas del profesor de Humanidades. Ejercicios durante las correcciones y Prelección el día de vacación.

7 Además de la selección de epigramas de la Antología Planudea, a Estienne se debe también una obra de importancia para los ejercicios escolares inspirados en estas composiciones: Progymnasma scholasticum [...] (Ver bibliografía). 
y la presencia, más o menos destacada de alabanza y vituperio como pretexto central del discurso. ${ }^{8}$ El éxito de muchos poetas del Siglo de Oro, e incluso su supervivencia, dependía a menudo de su habilidad para la práctica de géneros en que el encomio de sus protectores o el agudo vituperio de sus enemigos se supiese poner de manifiesto con habilidad y competencia. La práctica del epigrama (el género poético de mayor dificultad), y dentro de él las modalidades destinadas a alabanza o vituperio, era determinante para lograr el éxito anhelado. El poeta, pues, no perdía oportunidad de lucir su ingenio aprovechando las ocasiones de alabar o elogiar a personas de calidad (bien porque les debía algo, o porque esperaba alcanzar algo de ellos, o sencillamente porque los admiraba de veras). La misma oportunidad de cobrar renombre y prestigio de poeta se presentaba cuando se elaboraba un epigrama que vituperara vicios de alguien conocido; sería leído en público, repetido, copiado, y su autor pasaría a estar en boca de todos y cobraría renombre (en todos los casos está presente la condición de ostentación propia del género epidíctico a que hemos aludido). Entre los tipos de epigramas más propicios para esos logros está el epitafio, que como veremos podía ser usado tanto en su finalidad habitual, de duelo, como con finalidad satírica y burlesca.

\section{La preceptiva}

Entre los tratados de preceptiva sobre el epigrama en los siglos XVI y XVII, sólo algunos dedican consideraciones particulares al epitafio, pues la mayoría lo incluyen en las normas generales dadas para el epigrama como género. Entre las dos docenas de tratados que he consultado que contienen alguna reflexión o preceptiva sobre el epigrama entre 1548 y $1677^{9}$ destaca el tratado de Tommaso Corréa, portugués que enseñó Retórica en Palermo, Roma y Bolonia, y que fue el primero dedicado en exclusiva al epigrama. Se titula: De toto eo Poematis genere,

8 El género recibió los nombres de laudativo y demostativo también, pero algunos teóricos precisan que epidíctico no significa tanto demostración como ostentación y se diferencia mucho del encomiástico, pues sus límites no son tales como para contener sólo el género laudativo, sino que admite también el reproche. Frente a los otros dos géneros oratorios (el deliberativo y el judicial) el receptor de esta clase de discurso, que se ve realzado por medio del ornatus en la elocutio, no enjuicia la causa tratada por el orador, sino que es sensible al efecto artístico del discurso y a la exaltación de las virtudes. Su fin es lo bello y lo vergonzoso, mientras que el género deliberativo tiene como fin lo conveniente y lo perjudicial y la finalidad del género judicial es lo justo y lo injusto.

9 Robortello, Sebillet, Minturno, Julio César Escalígero, Tommaso Corréa, Jacobus Pontanus o Spanmüller, Antonio Possevino, Matthaeus Raderus, Vincenzo Gallo, Joannes Cottunius, Carolus Aconitanus a S. Antonio Patavino, Nicolas Mercier, Guillaume Colletet, François Vavasseur y Emmanuele Tesauro y los españoles López Pinciano, Baltasar de Céspedes, Luis Alfonso de Carvallo, Miguel Sánchez de Lima, Rengifo, Fernando de Herrera, Francisco Cascales, Gracián ... De ellos, los que ejercieron un mayor magisterio fueron el tratado de Minturno, De poeta ad Hettorem Pignatellum [...] libri sex, (Venecia, 1559), en cuyo libro quinto se trata del epigrama (en cinco páginas) y la Poetica de Julio César Escalígero (1561), cuya definición del epigrama y de sus peculiaridades es repetida por varios de los tratadistas posteriores al pie de la letra. 
quod Epigramma vulgo dicitur, y se publicó en Venecia en $1569 .{ }^{10}$ Corréa dedica el capítulo decimonono a De epitaphio y sigue hasta el capítulo vigésimotercio ocupándose de otras modalidades fúnebres de epigramas, como la nenia, el epicedio, la monodia y el treno.

Para Corréa, el epitafio es una modalidad del epigrama cuyo origen fue una oración fúnebre en la que se declaraban públicamente los hechos preclaros y gestas del difunto en beneficio de su patria. ${ }^{11}$ Dedica atención a las peculiaridades del estilo del epitafio, aunque le son propias las de todo epigrama.

Conviene recordar que el epigrama antiguo constituye una forma proteica, sujeta a un continuo proceso de ensanchamiento y absorción de otras formas literarias; se ocupa de varios asuntos - constatados ya en las primeras versiones de la Antología Griega ${ }^{12}$ - y admite realizaciones diferentes y una gran variedad en su forma, estilo y estructura. Aun así, una serie de marcas están presentes con asiduidad en todos los epigramas, y sólo algunos rasgos se destacan dependiendo de las diferentes modalidades. Por lo general, las marcas más constantes del género son:

- su concisión y concentración expresiva ${ }^{13}$

- la agudeza y el ingenio. ${ }^{14}$

- Articulación dicotómica en una primera parte (narratio - declaración de un hecho objetivo) seguida de un acumen o aprosdóketon - reflexión ingeniosa que

10 Luego fue impreso otra vez en 1590 en Bolonia, bajo el título abreviado de De epigrammate. Se basa en la teoría de Escalígero expuesta en sus Poeticas que había aparecido ocho años antes, pero amplía mucho y da detalles de enorme interés, sobre todo en lo que respecta al estilo y a las diferentes modalidades de epigramas. Corréa insiste en que se tomen como modelos los griegos de la Antología Planudea. Al parecer, el libro de Corréa fue eclipsado en popularidad e importancia por las Poeticae Institutiones (Ingolstadt, 1594) del jesuita Jacopus Pontanus (o Spanmüller). Agradezco a Fracisco Javier Escobar Borrego su ayuda en la traducción del latín del tratado de Corréa.

11 'Sunt praeterea quaedam genera epigrammatis, quae epitaphia dicuntur, quae fere in exornatione sunt posita. Est autem epitaphium inscriptio, quae in sepultura fit, quae docet, cuius ossa tegantur ea mole, quod eius plerunque nomen, aetas, dignitas, munus, facta et huismodi alia. Morem veterum indicat Virgilius [...]' (p. 56).

12 Recordemos que hubo varias versiones desde la realizada a comienzos del siglo I a.C. por Meleagro. La antología de Constantino Cephalas (h. el año 980 d.C.), que reunía las colecciones de Meleagro, de Philippus de Thessalonica (siglo I), Diogenianus (siglo II) y Agathias (siglo VI) incluye las siguientes modalidades epigramáticas en cuatro libros: epigramas amatorios, epigramas votivos, epitafios, epigramas descriptivos. E igualmente siguieron teniendo gran representación los epitafios en la versión de Máximo Planudes, de comienzos del siglo XIV y, por supuesto, en la versión Palatina, descubierta en 1606.

13 Las preceptivas defienden la breuitas, pero ha de tenerse en cuenta que ésta no depende del número de versos, como a veces se interpreta hoy, sino de que no haya nada superfluo, que se exprima la propiedad del lenguaje.

$14 \mathrm{El}$ ingenio a que se refieren los preceptistas es el que deriva de situaciones como guardar la explicación de la situación afrontada en la primera parte del epigrama y dejarla aparecer de manera súbita en el último verso, el uso de ambigüedades, un dicho agudo o sentencioso, y sobre todo, se consideraba como la más efectiva romper las expectativas del lector con el efecto sorpresa. Argutia y breuitas son las condiciones más inherentes al epigrama según Escalígero y otros teóricos renacentistas. 
concluye el poema). Eso es determinante a la hora de elegir una estrofa en español que pueda acoger las dos partes. ${ }^{15}$

- perfección técnica, que debía mostrarse en la cohesión de las partes del poema y en la propiedad del lenguaje (expresión concentrada). Elegancia y propiedad solían pedir los teóricos para el género.

- En el epitafio - y en otras modalidades epigramáticas - las voces del discurso interesan mucho y son variables: puede ser simple alocución, apóstrofe, diálogo, o una forma mixta de narración, dependiendo de quien emite el mensaje. Si en el resto de modalidades epigramáticas la prosopopeya aparece a menudo, en el epitafio es más frecuente.

- Otro rasgo en que insisten los preceptistas, tiene que ver con el genus oratorio, dependiendo de la finalidad de quien emite el mensaje y de la actitud que puede suscitar en el receptor. ${ }^{16}$ Los epitafios presentan, por lo general, preferencia por el genus demostrativo o epidíctico.

- El epigrama requiere un receptor cualificado, capaz de captar el ingenio sutil, la habilidad profesional del autor y su capacidad para utilizar la agudeza. Fue por ello propuesto como ejercicio de academia literaria y en certámenes y justas poéticas, a sabiendas de que quien lo realizara había de emplearse a fondo para demostrar su pericia como poeta.

- En cuanto a la finalidad, no parece haber discusión manifiesta. El poeta pretende sorprender, deleitar y en ocasiones, conmover. Por encima de cualquier otra consideración, el autor persigue exhibir su capacidad de ingenio conceptual y verbal. Es, pues, poesía de ocasión, enmarcada en el género del elogio, y como éste, susceptible de ser aplicado a la alabanza o, por el contrario, a una vituperatio. Por eso hallamos, y no por otra cosa, epitafios panegíricos y epitafios burlescos; es decir, los que se destinan a honrar al difunto, a cantar sus cualidades, o aquellos que lo único que pretenden es denostar a alguien que aún está vivo y al que se le castiga con el escarnio de leer su propio epitafio en que se señalan sus peores vicios.

Cuando un poeta español se ejercitaba en la práctica del epitafio tomando como modelos los clásicos, había de tener en cuenta todas esas peculiaridades genéricas para amoldar los rasgos al sistema poético español sin que perdiera ninguna de sus marcas características, ya fuera respecto a la estructura, la condición elocutiva, las voces del discurso, el estilo ...

$\mathrm{Al}$ igual que en la propia Anotología Griega, donde las fuentes de los epitafios eran diversas, desde los que reproducían los epigramas incisos en piedras sepul-

15 En realidad, la estructura del epigrama es variable (simple y compuesto): el simple, que hace una indicación sin presentar una deducción de ella (fórmula preferida por los Griegos y Catulo), y el compuesto (preferido por Marcial y sus seguidores) en que se deduce algo nuevo de lo que se indica en los primeros versos. Estos han de distribuirse bien entre la expositio o narratio y la clausula o conclusio.

16 Esta aplicación de las divisiones de la Retórica aristotélica al epigrama - y por tanto al epitafio - parece haberse originado con Escalígero y fue muy usada por sus seguidores. Se aplica principalmente al tipo de epigrama 'compuesto'. 
crales (como los que ofrece Cephalas) a los que no proceden de fuentes epigráficas (como los de Meleagro, Philippus y Agathias), los epitafios creados por los poetas españoles del Siglo de Oro eran con mucha frecuencia composiciones destinadas no a ser epitafios genuinos, es decir, escritos para grabar realmente en la lápida de una tumba, sino para ser expuestos como affixiones (carteles grandes que se colocaban en la iglesia durante las exequias del difunto, o en el catafalco - si se trataba de un noble o alguien de gran importancia pública) o, en la inmensa mayoría de los casos, no tenían más fin que el de ser un ejercicio literario con el que practicar el género epidíctico.

Ese carácter literario que fue adquiriendo el epitafio incrementó el número de quienes escribían el suyo propio cuando estaban vivos, como por ejemplo Hernando Colón (Varela 1983), o a realizar piezas literarias bien emotivas incluso para un animal, como hizo Lipsio para su perro Mopsus cuando murió escaldado (Papy 1999).

\section{La métrica}

Como es sabido, el metro latino habitual para los epigramas era el dístico elegíaco, que distribuía el contenido del texto en un número indeterminado de unidades autónomas constituidas por dos versos. Mientras que en la adaptación al español del sistema petrarquista la asociación entre marcas sémicas y las formal-métricas era estructural - y también en algunas otras adaptaciones de las realizaciones de origen grecolatino (por ejemplo, la oda asociada a la lira, el terceto a la elegía, etc.) - en la adaptación del epigrama, los poetas tuvieron que buscar cauces métricos existentes que pudieran acoger las marcas formales que acabo de indicar. Estaban condicionados por la necesidad de brevedad y la conveniencia de poder dividir la estrofa en dos bloques que recogieran la narratio y la conclusio en los epigramas compuestos y que, a la vez, se pudiera dar realce a la conclusión ingeniosa.

Los teóricos renacentistas dan sus consejos sobre el número de versos que convienen al epigrama - en que, naturalmente, se incluye al epitafio. Mientras que para Escalígero (1561), el epigrama admite todo tipo de versos, y no marca longitud, otros, como Minturno (1559) recomiendan, para el epigrama italiano, usar versos de 11 sílabas, o en combinaciones de 11 y 7 (con o sin rima); Tesauro aconseja usar entre dos y seis versos, aunque deja claro que lo único importante es que se acojan correctamente las dos partes del epigrama. Sebillet, inspirándose en la práctica de Marot, convenía en 1548 en que el epigrama francés no debía exceder de 12 versos y consideraba los de 8 y 10 sílabas los mejores, aunque admitía el alejandrino francés.

En España se produjo un importante proceso de adaptación métrica de las formas clásicas del epigrama a nuestro sistema entre 1550 y 1570, especialmente del de tradición humanística (fundamentalmente el epidíctico y el moral). Ello está bastante ligado al progresivo acaparamiento de los jesuitas de la enseñanza en las ciudades. 
Entre las estrofas más empleadas para la realización de epitafios en español está la copla castellana (o doble redondilla, en que a veces el final era una quintilla). Fue muy empleada, especialmente para los epitafios que parecen proceder de ejercicios literarios de jóvenes. Las dos partes intrínsecas a la forma epigramática podían acogerse fácilmente en las dos estrofas.

\section{EL CID}

Alarbes me dieron parias como a rey y emperador, y me llamaron señor del África partes varias.

La obediencia y el poder juntos conmigo vivieron; vivo nunca me vencieron, $\mathrm{y}$ muerto pude vencer. (Lope de Vega, La Arcadia)

\section{DEL PRÍNCIPE DON CARLOS}

Aquí dio fin un cometa que del mismo sol nació, con resplandor que mostró ser hijo de tal planeta.

Término breve y sucinto quiso el cielo que viviese, porque otro Carlos no hubiese que igualase a Carlos Quinto. (Lope de Vega, Rimas)

En estos epitafios de Lope de Vega vemos que la primera redondilla expone, los dos versos siguientes sirven de transición y se reservan los dos últimos para la agudeza, concentrada en el primero en la oposición paradógica vivo/muerto y en el segundo en la coincidencia del nombre Carlos.

Otra fórmula muy socorrida era la décima espinela, que por el rigor en la disposición, forma y desarrollo, se presta especialmente para los menesteres del epigrama, pues un corte de sentido después del cuarto verso es obligatorio, lo cual se ajusta a las demandas del género. En esa primera redondilla, se presenta el tema. Los seis versos que siguen no deben introducir ninguna idea nueva, sino ampliar el precedente planteamiento. Como en este ejemplo de Lope de Vega:

así quedaron sus pensamientos burlados, y Silvia, criando aquella desdichada prenda suya, que si creciere, como en las comedias, tendrá vuestra merced la segunda parte. Entre tanto, lea ese epitafio o elogio a su desdicha:

Aquí yace un desdichado,

Que, de sí mismo nacido,

Vivió por desconocido,

Murió por desconfiado.

Del propio honor engañado,

Aunque no sin culpa alguna, 
Dejó el sol, buscó la luna:

Donde se ve que el valor

Quiere a fuerza del honor

Resistir a la fortuna. ${ }^{17}$

Una estrofa que tuvo especial éxito entre los poetas que practicaban el epigrama en español fue la octava, pues se hacía particularmente propicia para reservar el pareado final al final ingenioso o didáctico, y era muy adecuada para recibir las dos partes del epigrama. Se ve muy a menudo que 4 versos se dedican a la narratio, los dos siguientes sirven de transición estableciendo una similitud entre dos situaciones y se reserva el pareado final para la conclusio. Sin embargo, en la modalidad del epitafio, la octava no fue tan usada como otras formas estróficas. La octava se reservó, sobre todo, para el tipo de epigrama moral, didáctico o emblemático. ${ }^{18}$

Un ejemplo de esta formulación estrófica nos la da Quevedo en un epitafio burlesco dedicado a un médico, compuesto seguramente cuando era muy joven, ya que Espinosa lo publicó en sus Flores de poetas ilustres (Valladolid, 1605). Obsérvese que habla la Muerte:

Yacen de un hombre en esta piedra dura el cuerpo yermo y las cenizas frías.

Médico fue, cuchillo de natura, causa de todas las riquezas mías.

Y agora cierro en honda sepultura los miembros que rigió por largos días, y aun con ser Muerte yo, no se la diera, si dél, para matarle, no aprendiera. ${ }^{19}$

Vemos aquí, pues, además del metro muy adecuado para cumplir con las necesidades de articulación dicotómica (narratio + acumen en el pareado final), lo sorprendente de la voz del discurso, que justifica la agudeza final: el médico es tan eficaz matando, que la propia Muerte tuvo que aprender de él para poder darle muerte.

Una estrofa que acogía bien las marcas del epigrama, y que se usó para el epitafio con frecuencia es el madrigal. Quevedo la empleo en varias composiciones, como por ejemplo en las que comienzan:

Lícito te será, buen caminante, [B 277]

Detén el paso y vista, mas no el llanto [B 280]

Esconde pobre losa [B 281]

Yace Faetón en esta tierra fría [B 822]

Yace en aqueste llano [B 635] madrigal formado en su mayor parte de pareados.

17 La desdicha por la honra, Novelas a Marcia Leonarda, 1623.

18 Para los precedentes italianos de la octava, ver Prieto 1984: 48 y 62-63. Para el empleo de la octava en epigramas emblemáticos, ver López Poza 1999.

19 Blecua, 820. A partir de ahora, para los epitafios de Quevedo citaré por la edición de José Manuel Blecua, 1970-1985, 4 vols, y lo señalaré así [B seguido del número de la composición en esa edición]. 
En ocasiones se dilata más allá de los quince versos hasta convertirse en lo que hoy denominamos silva, como este epitafio que Quevedo dedicó a Góngora, para mortificarle, cuando éste aún estaba vivo: Este que, en negra tumba rodeado [...] compuesto de treinta y siete versos en que predomina el gusto por la frecuencia de pareados.

Este que, en negra tumba, rodeado de luces, yace muerto y condenado, vendió el alma y el cuerpo por dinero, $\mathrm{y}$ aun muerto es garitero; y allí donde le veis, está sin muelas, pidiendo que le saquen de las velas.

Ordenado de quínolas estaba, pues desde prima a nona las rezaba; sacerdote de Venus y de Baco, caca en los versos y en garito Caco. La sotana traía por sota, más que no por clerecía.

Hombre en quien la limpieza fue tan poca (no tocando a su cepa), que nunca, que yo sepa, se le cayó la mierda de la boca. Este a la jerigonza quitó el nombre, pues después que escribió ciclópeamente, la llama jeringóngora la gente. Clérigo, en fin, de devoción tan brava, que, en lugar de rezar, brujuleaba; tan hecho a tablajero el mentecato, que hasta su salvación metió a barato.

Vivió en la ley del juego, y murió en la del naipe, loco y ciego; y porque su talento conociesen, en lugar de mandar que se dijesen por él misas rezadas, mandó que le dijesen las trocadas. Y si estuviera en penas, imagino, de su tahúr infame desatino, si se lo preguntaran, que deseara más que le sacaran cargado de tizones y cadenas, del naipe, que de penas. Fuése con Satanás, culto y pelado: ¡mirad si Satanás es desdichado! [B 840]

Además de lo que hemos comentado respecto a la métrica, este epitafio nos sirve para señalar cómo su autor hace uso de ostentación de agudeza verbal y pericia compositiva. A pesar de que sin duda puede calificarse de enorme mala fe dedicar un epitafio así a alguien que no se ha muerto, Quevedo sabía que le 
reportaría enorme popularidad en los círculos cortesanos. También nos sirve para advertir otra peculiaridad de estilo propia de las modalidades epigramáticas: la presencia de la deíxis, el uso de la prosopopeya, la libertad en el uso de la lengua que le incita a crear las formas 'jerigóngora', 'ciclópeamente', o los juegos de paronomasia (caca ... Caco), y algunos artificios de eco.

Una variante del madrigal que a Quevedo le gustó especialmente fue el ovillejo (silva en pareados, como explicó Antonio Alatorre 1990) que fue muy utilizado por Calderón y sus seguidores. Veamos un ejemplo:

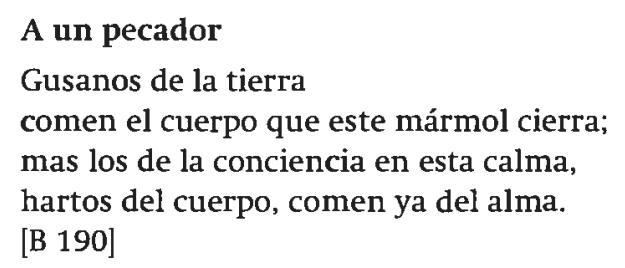

Y, por supuesto, el soneto. El soneto podía adaptarse bien para trasladar epigramas compuestos por cuatro dísticos; cada una de las subunidades estróficas que forman a su vez el soneto podía desarrollar uno de los dísticos en ejercicios de traducción o aemulatio. El momento culminante del poema, que solía ser el último dístico, quedaba así reflejado en el último terceto del soneto. Por su estructura bipartita y por la estima y admiración que despertaba la capacidad de escribir sonetos, fue una de las estrofas más empleadas en el siglo XVII para expresar epitafios, tanto en su faceta seria como en la burlesca.

\footnotetext{
Memoria soy del más glorioso pecho [B 244]

Blandamente descansan, caminante [B 245]

Columnas fueron los que miras huesos [B 246]

Entre las coronadas sombras mías [ В 239]

Lo que en Troya pudieron las traiciones [B 247]

Mi madre tuve en ásperas montañas [B 249]

Este, en traje de túmulo, museo, [B 253]

A la naturaleza, la hermosura [B 254]

Su mano coronó su cuello ardiente B 257]

No llegó a tanto invidia de los hados [B 259]

Las aves del Imperio, coronadas [B 260]

Rayo ardiente del mar helado y frío [B 262]

¿Quién alimentará de luz al día? [B 265]

Aqueste es el poniente y el nublado [B 268]

Si los trofeos al túmulo debidos [B 271]

$¿$ Ves las cenizas que en tan breve asiento [B 272]

Religiosa piedad ofrezca el llanto [B 273]

Por más que el Tiempo en mí se ha paseado [B 276]

Yacen en esta rica sepoltura [B 520]

Fue más larga que paga de tramposo [B 521]

Esta cantina revestida en faz [B 583]

Si cuna y no sepulcro pareciere [B 251]
}

Algunos ejemplos de epitafios epigramáticos de Quevedo en sonetos 
Veremos ahora sólo dos ejemplos de sonetos epitafios (uno de Lope y otro de Quevedo). Ambos han de considerarse como elogios a sendos personajes de la nobleza. El de Lope presenta una de las fórmulas admitidas en el epigrama para expresar las voces poéticas: el diálogo.

\author{
A la muerte del duque de Pastrana \\ - ¿Quién llora aquí? - Tres somos. Quita el manto. \\ — La Muerte soy. - ¿La Muerte? Pues ¿Qué lloras? \\ - Sí, que conté de sus fatales horas \\ a un César español término tanto. \\ - ¿Y tú, robusto? - Marte soy. - ¿Con llanto \\ el resplandor del claro arnés desdoras? \\ - Perdí por otras manos vencedoras \\ yo luz, España sol, Flandes espanto. \\ - Y tú, niño, ¿Quién eres? - Antes era \\ Amor, pero murió mi nombre y llama \\ muerto el más bello que la Fama escribe. \\ - Muerte, Amor, Marte, no lloréis que muera \\ don Rodrigo de Silva: que la fama \\ de su valor eternamente vive \\ Rimas, 100
}

Túmulo funeral de Federico, hermano del marqués Espínola

(Diole muerte la guarnición de su espada, teniéndola en la mano y peleando, con el golpe que en ella dio una bala de artillería.)

Blandamente descansan, caminante, debajo de estos mármoles helados, los huesos, en ceniza desatados,

del Marte ginovés, siempre triunfante.

No los pises, no pases adelante,

que es profanar despojos respetados, cuando no de la muerte, de los hados, que obligan a la Fama que los cante.

El rayo artificioso de la guerra, émula de virtud la diestra airada, en esta piedra a Federico cierra.

Que la muerte en el plomo disfrazada, no se la pudo dar en mar ni tierra, sin favor de su mano y de su espada. [B 245]

\title{
Efectos de estilo
}

Para conseguir la admiración del lector o escuchante, el poeta puede hacer uso de gran variedad de recursos retóricos y juegos con la lengua; dispone de más libertad en estos casos que para componer en otros géneros. Puede inventar palabras, usar términos extranjeros, crear palabras mixtas de dos (como indican Minturno y Escalígero). Varios preceptistas dedican especial atención al eco, que ven como un mecanismo interesante. 
Para Robortello, el autor había de usar los recursos precisos con tal de conseguir lepor (donaire, gracia) y sal (agudeza), y en cualquier caso, ha de pretender la propiedad del lenguaje - suavitas - y un uso oportuno de agudezas. Escalígero considera que todos los estilos (alto, bajo, medio) son admitidos y pueden ser compuestos.

Corréa juzga el epigrama superior a cualquier otra clase de poesía, e insiste en que cada palabra tiene mucha importancia. Por ello, el léxico ha de escogerse con sumo cuidado, y buscar la elegancia en la expresión. Junto a la argutia considera la venustas, suavitas, vehementia, energia (Corréa 1569: 31) como cualidades deseables. Y en especial, para el epitafio, indica que, en ocasiones, el poeta puede valerse de epifonemas exclamativos o interrogativos (Corréa 1569: 57). Recomienda indicar en ellos la causa de la muerte (peste, guerra ...), trayendo a colación el nombre de las Parcas, de Perséfone u otras divinidades mitológicas. Es necesario consolar a los allegados, amigos, etc., y rogar por un descanso feliz. Igualmente, se recomienda dirigirse al túmulo, al caminante (homo uiator), al lector (Corréa 1569: 58).

Habremos de lamentar - dice - la mudable fortuna. Dependiendo de la profesión del difunto, así se ha de manejar un léxico conveniente: si ha ejercido como soldado, habrá de estar presente Marte (Corréa 1569: 58). Hay que realizar, además, el elogio de sus virtudes y de los hechos conseguidos durante su vida.

Respecto a la estructura temática, según Corréa el epitafio consta de diversas partes: luto, alabanza, consolación, exhortación, explicación del daño y perjuicio, amplificación de los asuntos de manera que aumente el deseo por la persona desaparecida y consolación añadida (Corréa 1569: 59).

La deixis es otro elemento presente con mucha frecuencia en los epitafios, incluso en los de carácter literario, no destinados a inscripciones en lápidas. Ya hemos visto algunos hasta ahora. Veamos otros ejemplos.

Tenemos un epitafio de Quevedo 'A un poeta' que nos sirve para que observemos algunos de esos rasgos de estilo que le son propios al epitafio por ser precisamente un epigrama. En este ejemplo se emplea el diálogo, se da un juego ecoico y se expresa todo en un ovillejo.

\section{A un poeta}

- En esta piedra yace un mal cristiano.

- Sin duda fué escribano.

- No, que fué desdichado en gran manera.

- Algún hidalgo era.

- No, que tuvo riquezas y algún brío.

- Sin duda fué judio.

- No, porque fué ladrón y lujurioso.

- Ser ginovés o viudo era forzoso.

- No, que fué menos cuerdo y más parlero

- Ese que dices era caballero.

- No fué sino poeta el que preguntas,

y en él se hallaron estas partes juntas. [B 819] 
En este otro soneto epitafio, Quevedo juega con los sonidos de escasa frecuencia en rimas con la letra eñe y todos los versos se estructuran (a excepción del terceto final) en torno a comparaciones con el adverbio más y frases hiperbólicas. Todo ello persigue la ostentación de habilidad para provocar la risa con la perfección técnica.

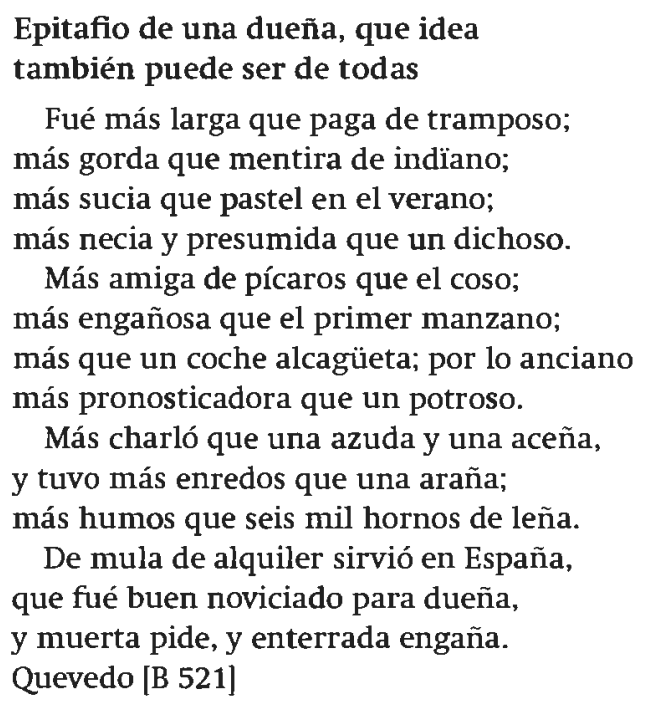

Todos estos rasgos son compartidos por las otras variedades epigramáticas fúnebres, que se diferencian fundamentalmente en que tenían carácter más oral que escrito - estaban pensados para ser oraciones o cánticos. Así, la Nenia es para Corréa otra modalidad epigramática, un tipo de epitafio antiguo, según Festo y San Agustín. Esta composición estaba destinada a ser cantada junto a la plaza (si se escribía era epitafio). En la nenia se explican muchas cosas, a saber, la incineración del difunto según la costumbre de los mayores, cómo había de cubrirse la sepultura, las cosas en relación a la estima, la lamentación y el luto. $^{20}$

El epicedio era un género epigramático que 'se decía' en las exequias. Corréa indica que, según Ammonio, cumplía la función de alabar al difunto en una actitud de conmiseración. ${ }^{21}$ El epicedio se contamina del elogio: 'Nonnunquam in epicedio est permixtum elogium, ut eo loco' (p. 62). Cuando se recitaba ante el túmulo, el epigrama no se llamaba epicedio sino epitafio.

La monodia se trataba de un canto lúgubre en el funeral para mover los afectos y hacer salir las lágrimas. No es el mismo género que el treno, ya que en la monodia se recuerda la memoria del difunto. Se solía cantar con la flauta o con

20 'Epitaphij nomine complectabantur veteres naeniam, quo nomine deam funerum, etiam appelabant, ut Festus et $S$. Augustinus docent. Dicebatur vero naenia epitaphium, seu carnem, quod ad rogum canebatur, si vero sepulturae in scriberetur, epitaphium' (p. 60).

21 'Epicedium erat carmen, quod pronunciabatur in exsequijs, dum solueretur iusta. Nam ut scribit Ammonio epicedia sunt, quae laudem de mortui continent cum commiseratione' (p. 61). 
el verso temperado por las modulaciones de los músicos. ${ }^{22}$

Por último, el treno es el canto de duelo o luto por una persona. Como es costumbre también en Sicilia, los allegados respondían en el canto en señal de duelo. El treno solían cantarlo los criados antes de sepultar al difunto.

Todas estas variedades epigramáticas fúnebres, como es sabido, las practicaron ampliamente nuestros autores del Siglo de Oro, haciendo una labor de adaptación de las fuentes griegas y latinas al español y nuestro sistema poético. Quevedo, por ejemplo, practicó con frecuencia el elogio funeral, el epitafio y otras modalidades epigramáticas fúnebres (túmulos así como la nenia, el treno, la monodia, el epicedio ...) prácticamente todos encuadrables dentro del genero epidíctico. Como propio de ese tipo de poesía de ocasión, Quevedo parece esforzarse en ostentar su capacidad, sobre todo en los dedicados a personajes de la historia o la fábula: Colón, Viriato, Jasón, Belisario, Mucio Scévola, Alejandro Magno, Aquiles, que presumiblemente compuso como ejercicios en su formación como poeta. Como ejemplo de alguno de los que parecen proceder de ejercicios escolares o de imitación, tenemos el dedicado a Jasón el argonauta, anterior a 1603 (Mi madre tuve en ásperas montañas), o el dedicado a Viriato, Memoria soy del más glorioso pecho, que luego fue adaptado para el sepulcro con las armas del duque de Osuna, en 1624. Esto sucede también con un soneto que dedica al túmulo de Luis Carrillo, en 1610, en que adapta uno casi igual, de $\mathbf{1 6 0 4}$ destinado a D. Bernardino de Mendoza. Sin embargo, en algunos de ellos la emoción o sentimiento afectivo por el difunto se manifiesta con claridad, como en el dedicado a un juez que fue bueno, Don Berenguel de Aois (lo que parecía excepcional a Quevedo):

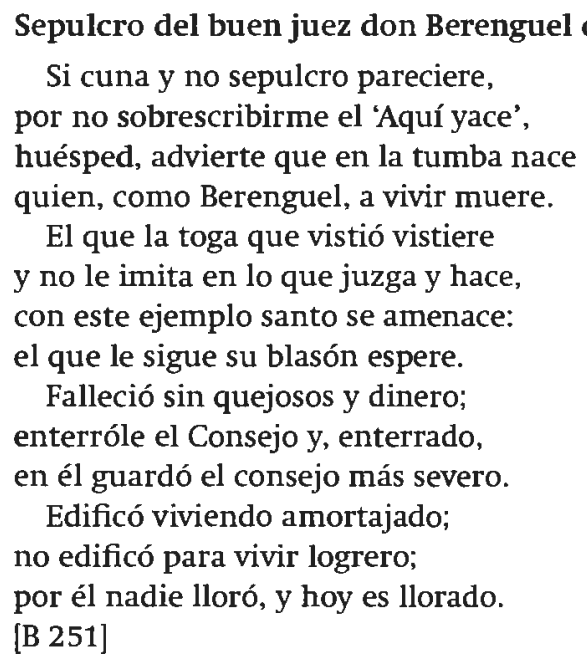

La alocución es predominante, lo que no es extraño limitándonos a este tipo de epigramas (la mayoría inscripciones en túmulos o en sepulcros) pero también hay prosopopeya en bastantes ocasiones, y diálogo en otras:

22 'Monodia item in funere intelligebatur. Erat autem carmen quod ab aliquo voce subtristi canebatur ad movendos affectus et eliciendas lacrymas [...] idque vel ad tibiam fiebat, vel versu musicorum modulis temperato' (p. 63). 
Memoria soy del mas glorioso pecho - habla el mármol al caminante

Entre las coronadas sombras mías - habla España a El Escorial

Lo que en Troya pudieron las traiciones - habla el autor al fallecido

Mi madre tuve en ásperas montañas - 'Habla un pedazo de la entena de su nave, en cuya

figura se supone esta prosopopeya' G.S. Habla, pues, el madero a un caminante.

Imperio tuve un tiempo, pasajero - Habla un pedazo de la nave donde descubrió el nuevo mundo.

En esta piedra yace un mal cristiano - (que ya hemos visto, expuesto en forma de diálogo).

La presencia del eco y de la deíxis es también fácilmente constatable, así como otros recursos como los verba videndi y otras fórmulas retóricas procedentes de los clásicos. A veces la deíxis es muy repetida en un mismo epitafio, como en 'Éste, en traje de túmulo, museo' dedicado por Quevedo al jurisconsulto y abogado don Francisco de la Cueva.

En este breve acercamiento al epitafio literario español de los siglos XVI y XVII, espero haber logrado transmitir lo que pretendía: que los géneros dominaban sobre cualquier otra consideración en el Siglo de Oro y que no pueden analizarse las piezas poéticas sin antes emarcarlas en el contexto histórico en que fueron producidas y sin tener en cuenta la praxis a que dedicaban nuestros autores tantísimas horas, días y años. Quiero subrayar que los aciertos no se deben, como a veces parece sugerirse, a simples golpes de inspiración del poeta, sino que éste estaba muy condicionado en el Siglo de Oro para emplear unos rasgos u otros tanto en métrica, como en estilo, como en estructura, etc. vinculados al género en que iba a expresarse, y que el del epitafio se enmarcaba en el epigramático, derivado de la Antología Planudea o de quienes la habían imitado durante siglos. Ser competente en su creación, su adecuada lectura y comprensión era parte del equipamiento intelectual de toda persona educada en los siglos XVI y XVII. En cada una de estas obras se encierra todo un patrimonio cultural formal y conceptual que es preciso no olvidar, a pesar de que hoy nos resulte tan difícil realizar el camino inverso para encontrarnos con las claves que alentaron su construcción.

\section{Obras citadas}

Alatorre, Antonio, 1990. 'Perduración del ovillejo cervantino', NRFH, 38. 2: 643-74.

Corréa, Tommaso, 1569. De toto eo Poematis genere, quod Epigramma vulgo dicitur (Venecia: Ex officina Francisci Ziletti).

Epigrammata aliquot Graeca Veterum Elegantissima, 1525. Eademque Latine ab utriusque linguae viris doctissimis versa, atque nuper in rem studiosorum e diversis autoribus per Joannem Soterem collecta, nuncque primum edita (Coloniae: J. Soler). A esta edición siguieron otra de Colonia en 1528 , y en Friburgo en 1544.

Epigrammata graeca, 1570. Selecta ex Anthologia, interpretata ad [...]erbum et carmine ab Henrico Stephano; quaedam ab aliis. Loci aliquot ab eodem annotationibus illustrati. Ejusdem interpretationes centum et sex unius distichi; aliorum item querundam epigrammatum variae (S.L.: excudebat Henricus Stephanus).

Gil, Eusebio, ed., 1992. El sistema educativo de la Compañía de Jesús, La 'Ratio Studiorum', edición bilingüe, estudio histórico pedagógico, bibliografía (Madrid: UPCO). 
López Poza, Sagrario, 1999. 'El epigrama en la literatura emblemática española', Analecta Malacitana, Universidad de Málaga, 22.1: 27-55.

— - 2005. 'La difusión y recepción de la Antología Griega en el Siglo de Oro', en En torno al canon: aproximaciones y estrategias (VI Encuentro Internacional sobre Poesía del Siglo de Oro), ed. Begoña Lopez Bueno (Sevilla: Servicio de Publicaciones de la Universidad / Grupo PASO), pp. 15-67.

Papy, Jan, 1999. 'Lipsius and his Dogs: Humanist Tradition, Iconography and Rubens's Four philosophers', Journal of the Warburg and Courtauld Institutes, 62: 167-98.

Prieto, Antonio, 1984. La poesía española del siglo XVI, I (Madrid: Cátedra).

Progymnasma scholasticum, 1597. Hoc est, Epigrammatum Graecorum, ex anthologia selectorum ab He. Stephano, duplicique ejusdem interpretatione explicatorum praxis grammatica, ordine facili $\varepsilon$ perspicuo, omnia qu in his occurrunt alicuius momenti $\&$ difficultatis vocabula explanans, $\delta$ enodans, ad magnum tam docentium quam discentium emolumentum \& levamen. Opera \& industria Iohannis Stockvvoodi, schol Tunbridgiensis olim ludimagistri. Graeca praeterea sunt omnia per lineas interlineares Latinis expressa typis, ad faciliorem eorundem lectionem, in studios juventutis gratiam (Londini: Ex typographia Adami Islip).

Quevedo, Francisco de, 1970-1985. Obra poética, edición de José Manuel Blecua, (Madrid, Castalia), 4 vols.

Selecta epigrammata graeca latine versa, ex septem Epigrammatum Graecorum libris, 1529. (Basileae: ex aedibus Io. Bebelii).

Tesauro, Emanuele, 1741. Cannocchiale Aristotelico, esto es, anteojo de larga vista o idea de la agudeza e ingeniosa locucion que sirve a toda arte oratoria, lapidaria y symbolica, examinada con los principios del divino Aristóteles [...] traducido al español por [...] Fr. Miguel de Sequeyros (Madrid: Antonio Marin).

Varela, Consuelo, 1983. 'La obra poética de Hernando Colón', Anuario de Estudios Americanos, 40: 185-201. 